See Article page $\mathrm{XXX}$.

\section{Commentary: Pulmonary complications in cardiothoracic surgery: Risk stratification is good; risk modification is better}

\author{
Edward Buratto, MBBS, PhD, FRACS, ${ }^{\mathrm{a}, \mathrm{b}, \mathrm{c}}$ \\ Antonia Schulz, MD, ${ }^{\mathrm{a}}$ and \\ Igor E. Konstantinov, MD, PhD, FRACS ${ }^{\mathrm{a}, \mathrm{b}, \mathrm{c}, \mathrm{d}}$
}

Prediction of respiratory complications after cardiothoracic surgery is of great importance. However, it has become increasingly apparent that the European System for Cardiac Operative Risk Evaluation (ie, EuroSCORE) II and Society of Thoracic Surgeons short-term risk calculator do not adequately assess postoperative risk of respiratory complications. ${ }^{1,2}$ Yet, pulmonary complications are one of the major contributors to morbidity and length of hospital stay following cardiothoracic surgery.

In this issue of the Journal, Khanna and colleagues ${ }^{3}$ report a novel nomogram for the prediction of postoperative pulmonary complications following cardiothoracic surgery, derived from a cohort of more than 17,000 patients who underwent surgery at the Cleveland Clinic between 2009 and 2015. After identifying risk factors for pulmonary complications on multivariable logistic regression, they developed a nomogram that demonstrated an excellent predictive value. Interestingly, they observed that the use of inhaled nitric oxide or prostacyclin analogues and intra-aortic conterpulsation were the strongest predictors of pulmonary complications.

The association of inhaled pulmonary vasodilators such as nitric oxide and prostacyclin analogs with adverse pulmonary outcomes is not surprising. These agents are typically used in patients with elevated pulmonary pressures, right ventricular

\footnotetext{
From the ${ }^{\mathrm{a} D e p a r t m e n t}$ of Cardiac Surgery, Royal Children's Hospital; ${ }^{\mathrm{b}}$ Department of Paediatrics, University of Melbourne; 'Heart Research Group, Murdoch Children's Research Institute; and ${ }^{\mathrm{d}}$ Melbourne Centre for Cardiovascular Genomics and Regenerative Medicine, Melbourne, Australia.

Disclosures: The authors reported no conflicts of interest.

The Journal policy requires editors and reviewers to disclose conflicts of interest and to decline handling or reviewing manuscripts for which they may have a conflict of interest. The editors and reviewers of this article have no conflicts of interest.

Received for publication Sept 7, 2021; revisions received Sept 7, 2021; accepted for publication Sept 7, 2021.

Address for reprints: Igor E. Konstantinov, MD, PhD, FRACS, Royal Children's Hospital, Flemington Rd, Parkville 3052, Australia (E-mail: igor.konstantinov@rch. org.au).

J Thorac Cardiovasc Surg 2021; $\mathbf{\square}: 1-2$ $0022-5223 / \$ 36.00$

Crown Copyright $(\subset) 2021$ Published by Elsevier Inc. on behalf of The American Association for Thoracic Surgery

https://doi.org/10.1016/j.jtcvs.2021.09.006
}

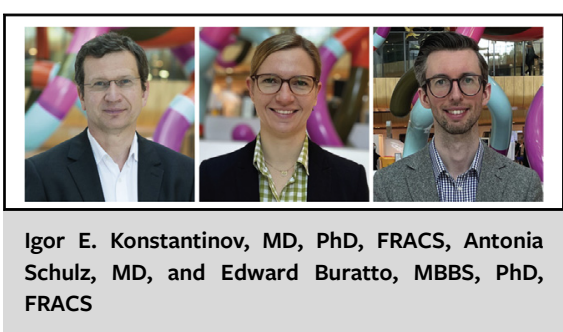

CENTRAL MESSAGE

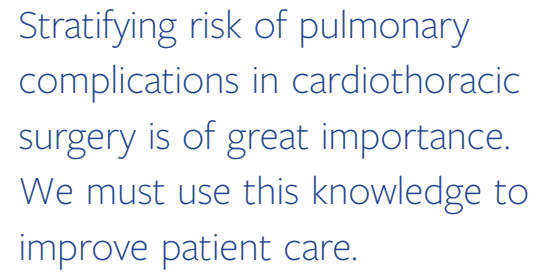

dysfunction, and difficulty weaning from bypass. In addition, they are often employed in patients in whom elevated leftsided pressures drive right ventricular failure, as a last resort to improve hemodynamics. It is predictable that these patients would have prolonged intubation times, which may not be related to the pulmonary pathology per se. Indeed, although clinically significant benefits for these inhaled therapies have not been clearly established, ${ }^{4}$ they have been demonstrated to reduce pulmonary resistance and improve right ventricular ejection fraction. ${ }^{5}$ As such, it is important not to consider these findings as evidence for harm of inhaled pulmonary dilators. A more likely explanation is that despite multivariable adjustment, the need of pulmonary dilators reflects a high-risk group of patients with postoperative low cardiac output.

In contrast to the "get well soon"-type of balloon, intraaortic balloon pumping (IABP) is not offered just to cheer the patient up. The IABP is placed for severe left ventricular systolic dysfunction and borderline hemodynamics. Indeed, IABP is recommended as the first-line mechanical circulatory support for patients with ischemic cardiomyopathy undergoing coronary artery bypass surgery. ${ }^{6}$ Again, this is a very high-risk group, and these patients are likely to be at risk of pulmonary complications due to their severe hemodynamic compromise. Furthermore, patients with an IABP can almost never be extubated within 48 hours of surgery, and, thus, would always be counted as having pulmonary complications in the model. To simplify, it is not surprising that patients with IABP had high risk of pulmonary complications, but this does not mean that IABP was the cause of these complications. Similarly, the administration of nitric oxide and other pulmonary vasodilators in these sick patients is a reflection of a desperate attempt to improve pulmonary blood flow and, thus, ventricular filling to improve cardiac output. 
It would be far stretch to conclude that in these patients the nitric oxide or other pulmonary vasodilators would be a primary cause of pulmonary complications.

The strong predictive value of inhaled pulmonary vasodilators and IABP highlight the shortcomings of risk prediction models derived from retrospective cohorts. ${ }^{7}$ These therapies are used in the sickest patients, and, thus, their association with complications is subject to confounding.

The work of Khanna and colleagues ${ }^{3}$ is an important step forward in improving our ability to stratify patients who are at increased risk of postoperative pulmonary complications. In isolation, risk prediction is helpful in benchmarking, ensuring quality control, and resource allocation. It would also be helpful if those risk factors be modifiable. One should always be cautious to avoid interpreting correlation as causation. Risk-stratification studies are undoubtedly very important. It is upon us to interpret these studies for the benefits of our patients.

\section{References}

1. Shahian DM, Jacobs JP, Badhwar V, Kurlansky PA, Furnary AP, Cleveland JC Jr, et al. The Society of Thoracic Surgeons 2018 adult cardiac surgery risk models: part 1—background, design considerations, and model development. Ann Thorac Surg. 2018;105:1411-8.

2. Nashef SA, Roques F, Sharples LD, Nilsson J, Smith C, Goldstone AR, et al. EuroSCORE II. Eur J Cardiothorac Surg. 2012;41:734-44; discussion 744-5.

3. Khanna AK, Kelava M, Ahuja S, Makarova N, Liang C, Tanner D, et al. A nomogram to predict postoperative pulmonary complications after cardiothoracic surgery. J Thorac Cardiovasc Surg. XXX, 2021 [Epub ahead of print].

4. Elmi-Sarabi M, Deschamps A, Delisle S, Ased H, Haddad F, Lamarche Y, et al. Aerosolized vasodilators for the treatment of pulmonary hypertension in cardiac surgical patients: a systematic review and meta-analysis. Anesth Analg. 2017; 125:393-402.

5. Sardo S, Osawa EA, Finco G, Gomes Galas FRB, de Almeida JP, Cutuli SL, et al. Nitric oxide in cardiac surgery: a meta-analysis of randomized controlled trials. $J$ Cardiothorac Vasc Anesth. 2018;32:2512-9.

6. Bakaeen FG, Gaudino M, Whitman G, Doenst T, Ruel M, Taggart DP. 2021: the American Association for Thoracic Surgery expert consensus document: coronary artery bypass grafting in patients with ischemic cardiomyopathy and heart failure. J Thorac Cardiovasc Surg. 2021;162:829-50.

7. Buratto E, Shi WY, Konstantinov IE. The pearls and perils of settling scores in public. Semin Thorac Cardiovasc Surg. 2016;28:434-5. 